\title{
ALTERAÇÕES TÊMPORO-ESPACAIS EM CANAIS FLUVIAIS URBANOS (1908-2012): O CASO DA SUB-BACIA DO CANAL DO CUNHA (RJ)
}

\author{
Luisa Schneider Moreira Dias ${ }^{(a)}$,Sandra Baptista da Cunha ${ }^{(b)}$ \\ ${ }^{(a)}$ Mestre em Geografia, Departamento de Geografia, Universidade Federal Fluminense, luisa.smd@hotmail.com \\ (b) Profa. do PPGG, Departamento de Geografia, Universidade Federal Fluminense, sandracunha@ openlink.com.br
}

\section{EIXO: BACIAS HIDROGRÁFICAS E RECURSOS HÍDRICOS: ANÁLISE, PLANEJAMENTO E GESTÃO}

\begin{abstract}
Resumo
O processo de urbanização ocorrido na cidade do Rio de Janeiro transformou os canais fluviais. Anterior à urbanização, os rios da cidade eram mêandricos e sinuosos. Os rios foram canalizados, aterrados e/ou cobertos pela malha urbana. $\mathrm{O}$ objetivo deste trabalho consiste em analisar as mudanças de densidade de drenagem (Dd) e densidade hidrográfica (Dh) ocorridas na Sub-bacia do Canal do Cunha decorrentes das intervenções antrópicas, no período entre 1908 e 2012. O trabalho foi realizado através do levantamento cartográfico (cartografia histórica e atual), georreferenciamento e mensuração dos parâmetros morfométricos ( $\mathrm{Dd}$ e $\mathrm{Dh}$ ). A pesquisa demonstrou que a rede de drenagem - submetida à urbanização - apresentou mudanças no padrão de drenagem ao longo do século XX, assim como, a Dd e Dh sofreram alterações. O conhecimento prévio de como eram estes rios e suas características morfológicas poderão auxiliar projetos de planejamento urbanístico e ambiental, para assim, melhor gerir a subbacia.
\end{abstract}

Palavras chave: Bacia Hidrográfica. Densidade de Drenagem. Densidade Hidrográfica.

\section{Introdução}

A análise morfométrica em bacias hidrográficas define-se por um conjunto de metodologias através de parâmetros - que buscam investigar a compreensão científica dos elementos naturais de uma bacia de drenagem (IBGE, 2009). Segundo IBGE (2009), 'os estudos relacionados aos cursos fluviais por meio de métodos sistêmicos e racionais como parâmetros quantitativos podem levar ao esclarecimento de várias questões acerca da morfogênese e morfordinâmica da paisagem'. Desta forma, o método de análise morfométrica procura avaliar características das formas, processos e suas interrelações dos componentes de uma bacia hidrográfica, através do método quantitativo.

Este método é amplamente aplicado em análises das ciências hidrológicas e geomorfológicas.Segundo o IBGE (2009), alguns destes métodos 'possibilitam gerar informações passíveis de utilização em generalizações sobre bacias". Através da análise morfométrica é possível realizar o reconhecimento da espacialidade do sistema e às características da área e rede de drenagem de uma bacia hidrográfica. 
XVII Simpósio Brasileiro

de Geografia Física Aplicada

I Congresso Nacional

de Geografia Física
OS DESAFIOS DA GEOGRAFIA FÍSICA NA FRONTEIRA DO CONHECIMENTO

Instituto de Geociências - Unicamp

Campinas - SP

28 de Junho à 02 de Julho de 2017

Segundo Christofoletti (1980), os tipos de análises morfométricas em bacias hidrográficas se enquadram nas seguintes categorias: análise linear em rede hidrográfica, análise hipsométrica, análise topológica e análise areal em bacias hidrográficas. Todas estas tipologias de análise têm suas propriedades particulares. Os parâmetros morfométricos densidade de drenagem e densidade hidrográfica correspondem à análise areal em bacias hidrográficas, e que segundo o mesmo autor, esta análise engloba 'vários parâmetros nos quais intervêm medições planimétricas, além de medições lineares, como área da bacia, comprimento da bacia, densidade de segmentos da bacia, densidade de drenagem, densidade hidrográfica, etc".

O parâmetro morfométrico densidade de drenagem $(\mathrm{Dd})$ corresponde à relação entre o comprimento total dos rios com a área de sua respectiva bacia hidrográfica (CHRISTOFOLETTI, 1980; GUERRA, 2008). Segundo Christofoletti (1980), “'a densidade de drenagem foi inicialmente definida por R. E. Horton $(1945)^{1}$, podendo ser calculada pela equação Dd = L1/A, na qual Dd significa densidade de drenagem, L1 é o comprimento total dos canais e A é a área da bacia'. De acordo com o mesmo autor, para a análise de bacias hidrográficas, o cálculo da densidade de drenagem apresenta a relação inversa com o comprimento dos rios, ou seja, conforme se aumenta o valor da densidade há diminuição quase proporcional do comprimento dos canais fluviais das bacias de drenagem.

Para Linsley et al. (1975 apud BORSATO \& MARTORI, 2004)², a Dd elevada reflete uma bacia altamente dissecada, que responde de maneira relativamente rápida a uma determinada quantidade de chuva, enquanto uma Dd baixa reflete uma bacia de drenagem pobre com respostas hidrológicas lentas. Ainda de acordo com os autores, a densidade alta pode ser observada em bacias com solos facilmente erodíveis ou relativamente impermeáveis, declividades altas e as coberturas vegetais ralas.

A densidade hidrográfica (Dh), - também chamada de frequência de canais (f) ou densidade de rios (Dr) - é a relação existente entre o número de segmentos de rios ou cursos d'água e a área da bacia de drenagem (CHRISTOFOLETTI, 1980; GUERRA, 2008). Para estes autores, a finalidade deste parâmetro é comparar a quantidade e frequência dos rios existentes em uma área de tamanho padrão (unidade de área), como o quilometro quadrado.

Segundo Christofoletti (1980), este parâmetro foi desenvolvido - primeiramente - por Horton $(1945)^{1}$, sendo calculado pela fórmula $\mathrm{Dh}=\mathrm{N} / \mathrm{A}$, onde Dh é considerada a densidade hidrográfica, N é o número total de segmentos de rios ou cursos de água e A é a área da bacia considerada. Para tanto, é necessário realizar a ordenação de rios através dos critérios de hierarquização. De acordo com o mesmo autor, se for utilizado a ordenação de Strahler $(1952)^{3}$, '’o número de canais corresponde à quantidade de rios de primeira ordem, pois implica que todo e qualquer rio surge de uma nascente". 


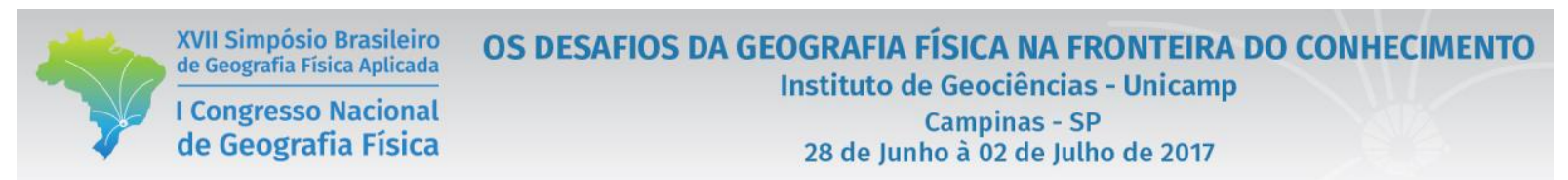

Cunha (2010), ao pesquisar sobre os rios urbanos no Brasil, constata que o número e comprimento dos rios foram reduzidos em função das obras de desvios dos canais, canalizações e/ou extinção dos mesmos, alterando os valores de densidade de drenagem e densidade hidrográfica. Este fato demonstra, pelas mesmas razões, que o processo de urbanização e as consequentes obras de engenharia nos canais fluviais fez com que se alterassem os valores de Dd e Dh na área de estudo.

Neste contexto, o objetivo deste trabalho consiste em analisar as mudanças de Dd e Dh ocorridas na Sub-bacia do Canal do Cunha decorrentes das intervenções antrópicas, no período entre 1908 e 2012.

\section{1. Área de Estudo}

A cidade do Rio de Janeiro está dividida em quatro grandes compartimentos hidrográficos: Sepetiba, Jacarepaguá, Zona Sul e Baía de Guanabara, sendo formados cada um deles por um conjunto de sub-bacias. A área de estudo (Sub-bacia do Canal do Cunha) insere-se no compartimento da Baía de Guanabara (figura 1), situada na zona norte da cidade, entre os paralelos $22^{\circ} 51^{\circ}$ e $22^{\circ} 55^{\circ}$ latitude sul e os meridianos de $43^{\circ} 15^{\circ}$ e $43^{\circ} 20^{`}$ de longitude oeste.

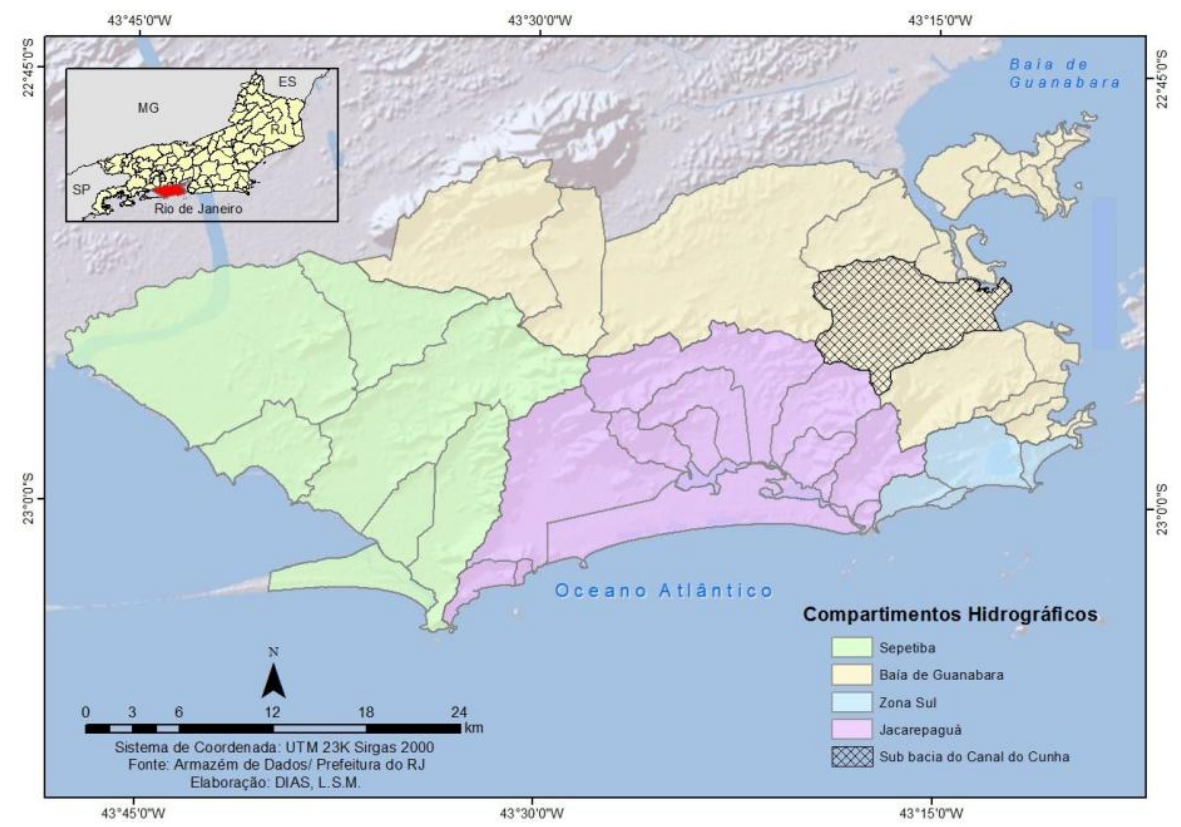

Figura 1: Compartimentos hidrográficos do município do Rio de Janeiro. Em destaque a Sub-bacia do Canal do Cunha.

A partir de 1922 ocorreram sucessivos aterros nas areas de baixada da Sub-bacia, próximo ao deságue do Canal do Cunha na Baía de Guanabara, para o favorecimento da ocupação e das instalações urbanas. Estas intervenções somaram à area de estudo $4,8 \mathrm{~km}^{2}$. 


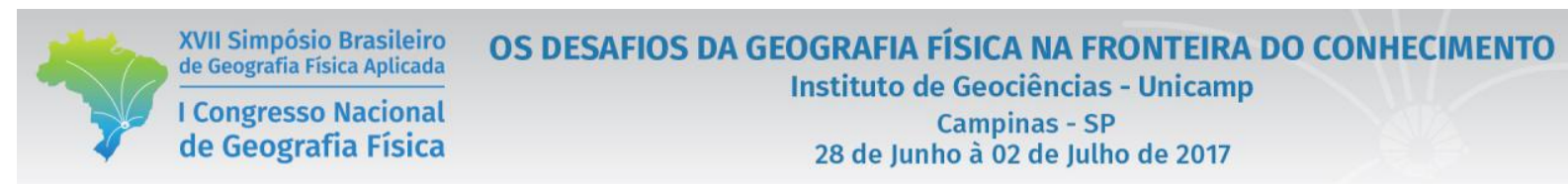

A ocupação da Sub-bacia é predominantemente urbana. Os 29 bairros totalmente inseridos na subbacia totalizam 743.085 habitantes (CENSO, 2010), tendo assim, a densidade demográfica de 11.776 habitantes por $\mathrm{km}^{2}$. Dentre os bairros mais populosos, encontram-se: Méier (49.828), Inhaúma (45.698), Engenho de Dentro (45.540), Piedade (43.378) e Cachambi (42.415), enquanto os bairros que possuem as maiores densidades demográficas, são Jacarezinho (40.254 hab/km²) e Todos os Santos $(24.401$ hab/km²).

A figura 2 apresenta os rios que compõem a área de estudo. O rio de maior extensão é o rio Jacaré $(8,3 \mathrm{~km})$. O percurso deste rio transpassa os bairros de Jacarepaguá (nascente), Lins de Vasconcelos, Engenho Novo, Jacaré e Jacarezinho. O de menor extensão é o rio dos Frangos (2,5 km). Este rio é um afluente do rio Faria. Todos estes rios encontram-se poluídos.

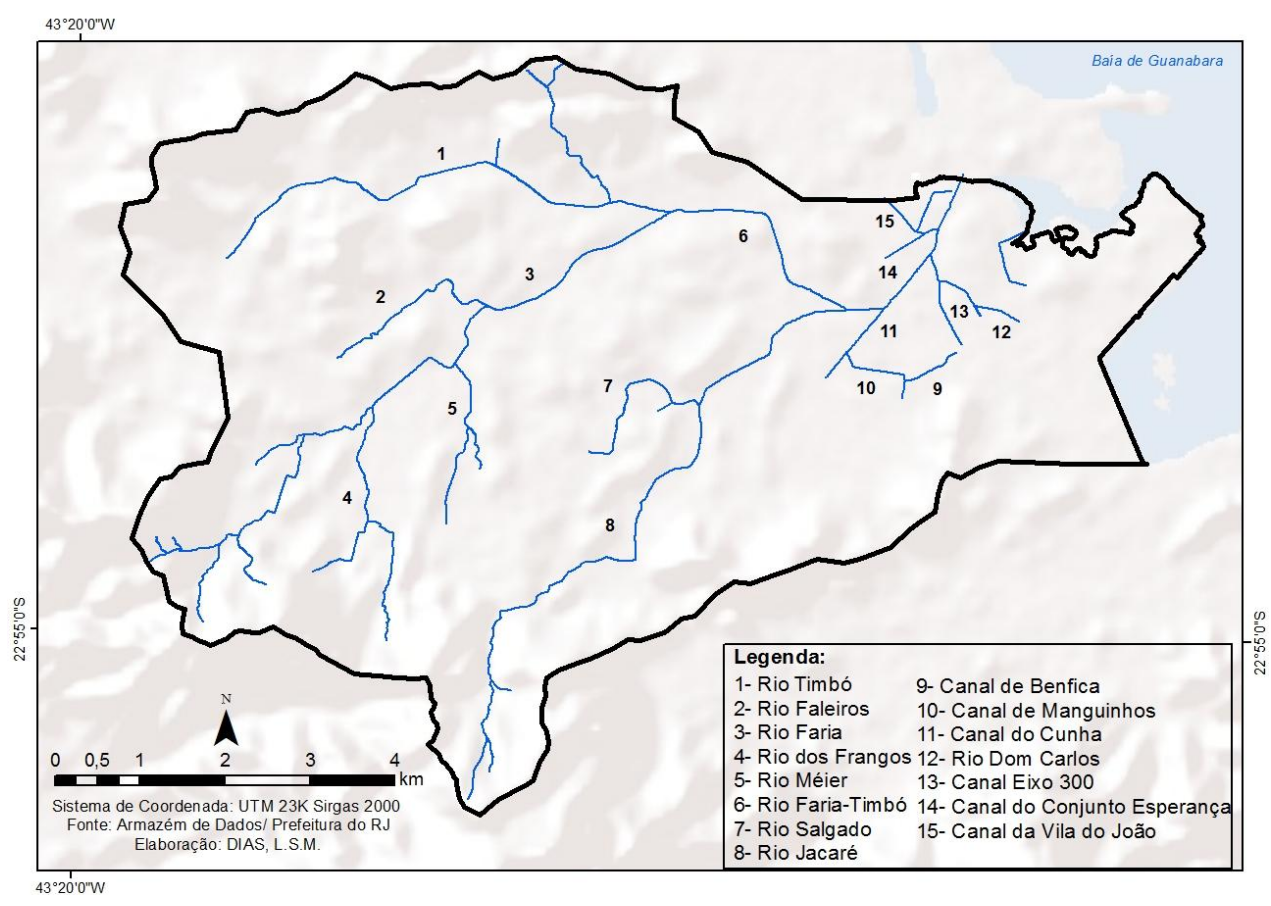

Figura 2: Rede hidrográfica da Sub-bacia do Canal do Cunha.

\section{Procedimentos Metodológicos}

Para analisar as mudanças de densidade de drenagem e densidade hidrográfica na Sub-bacia do Canal do Cunha, no período entre 1908 e 2012, foram organizadas em etapas: levantamento da cartografia histórica, georreferenciamento e mensurações dos parâmetros morfométricos (Dd e Dh).

O levantamento de plantas, cartas e mapas antigos da cidade do Rio de Janeiro entre os anos de 1800 a 1995 foram realizados em duas importantes instituições públicas: Arquivo Nacional e Biblioteca Nacional, levando em consideração se o material da cidade abrangia a área de estudo. Sendo assim, foram adquiridos 16 mapas antigos. 
De posse do material cartográfico antigo da bacia hidrográfica foi realizada uma análise crítica para seleção dos mapas e plantas. Adotou-se como critério de seleção: abrangência da área da Sub-bacia do Canal do Cunha, nível de informação, escala e ano do mapa. Após o crivo foi selecionada a Planta da cidade do Rio de Janeiro, organizada pela Repartição da Carta Cadastral do Distrito Federal (1908) adquirida no Arquivo Nacional. A Planta da Cidade do Rio de Janeiro (1908), a mais antiga da seleção, é a que possui maior nível de informação e qualidade elevada, além de contemplar a área de estudo com grande abrangência. Esta Planta, apesar de possuir bom nível de informação, não contempla dois afluentes em sua cartografia: rio Faleiros e rio Salgado.

Após o crivo de seleção, a planta foi georreferenciada através do software ArcGis desktop 10. A base cartográfica para o georreferenciamento foram as ortofotos do Instituto Pereira Passos (2012; 1:2.000; Datum Sirgas 2000). As articulações das ortofotos (261 E, 261 F, 262 E, 286 A, 286 B, 287 A e 286 D) compreendem por completo a sub-bacia do Canal do Cunha. O georreferenciamento foi executado com base nos pontos de controle existentes - à época e atual - para que coincidissem. Nesta etapa, teve-se como apoio o Google Maps que indicou o nome das vias.

Foi criada uma camada de vetorização (em linhas) da rede de drenagem com a planta de 1908 (georreferenciada). E para realizar o mesmo processo de vetorização dos rios correspondentes ao ano de 2012, foi utilizado as ortofotos do Instituto Pereira Passos (1:2.000, Datum Sirgas 2000), através do software ArcGis desktop 10. Foram considerados apenas os rios e canais que estão abertos, ou seja, descartou-se os rios cobertos.

Através das informações geradas pela reconstituição da rede de drenagem (1908) e drenagem atual (2012) dos rios da sub-bacia foi possível realizar as mensurações dos parâmetros morfométricos selecionados. Foram quantificadas as mudanças naDd eDh. Estes dois parâmetros - respectivamente serviram para verificar os números e os comprimentos dos canais, e foram calculados de acordo com a hierarquia dos canais segundo Strahler (1952, apud CHRISTOFOLETTI, 1980) ${ }^{3}$.Estes parâmetros foram utilizados de modo a quantificar as consequências da urbanização sobre o ambiente fluvial da área de estudo, por apresentarem alterações nos componentes hidrográficos.

Para a comparação espaço-temporal destes parâmetros, dividiu-se a sub-bacia em três áreas distintas: a) a sub-bacia com a antiga linha de costa (1908); b) a sub-bacia em sua forma atual (2012), ou seja, com a área de aterro inserida e, por fim, c) separadamente, a área que foi aterrada. Estas áreas detêm valores diferenciados, onde a primeira tem $58,3 \mathrm{~km}^{2}, 63,2 \mathrm{~km}^{2}$ e 4,8 $\mathrm{km}^{2}$ - em respectiva.

Para que os resultados fossem mais fidedignos, foi retirada a drenagem contida em 2012 em que o mapa de 1908 não contempla. É importante ressaltar que parte da bacia a sudoeste não foram computados 
os parâmetros, uma vez que, a planta de 1908 não incluía a drenagem nesta área. Além disso, na planta de 2012 não foram computados os rios Faleiros (afluente do rio Faria) e Salgado (afluente do rio Jacaré), por não constarem na carta de 1908. Estes não são canais que foram construídos, como é o caso dos canais existentes na área de aterro. Com isso, foram alcançados valores de Dd e Dh próximos da realidade.

\section{Densidade de Drenagem e Densidade Hidrográfica}

Ao longo dos 104 anos que separam os anos de 1908 e 2012 notaram-se mudanças têmporoespaciais no ambiente fluvial da Sub-bacia do Canal do Cunha, induzidas pelas intervenções antrópicas. Além das alterações nas formas, o número e o comprimento dos canais também foram afetados. Segundo Antoneli \& Thomaz (2007), os parâmetros morfométricos podem revelar indicadores físicos específicos para um determinado local, de forma a qualificar as alterações ambientais ocorridas na bacia.

Os valores da Dh evidenciaram diferenças nas três áreas de análise (tabela 1). Ao comparar o número de canais da sub-bacia em sua antiga delimitação $\left(58,3 \mathrm{~km}^{2}\right)$, houve redução do número de canais em 2012. Em 1908 haviam 26 rios - 19 canais de $1^{\text {a }}$ ordem, 6 de $2^{\text {a }}$ ordem e 1 de $3^{\text {a }}$ ordem. A rede de drenagem em 2012 apresenta 15 canais fluviais, ou seja, 11 canais a menos comparada à área da sub-bacia atual. Nesta antiga configuração da Sub-bacia, a densidade hidrográfica em 1908 tem o valor de 0,44 canais $/ \mathrm{km}^{2}$, enquanto em 2012 de 0,25 canais $/ \mathrm{km}^{2}$, ou seja, 0,19 canais $/ \mathrm{km}^{2}$ a menos. Porém, este valor é alterado ao utilizar a delimitação atual da sub-bacia $\left(63,2 \mathrm{~km}^{2}\right)$.

Tabela 1: Número de canais e a densidade hidrográfica (Dh).

\begin{tabular}{|c|c|c|c|c|c|}
\hline \multirow{2}{*}{$\begin{array}{c}\text { Hierarquia dos } \\
\text { Canais }\end{array}$} & \multicolumn{5}{|c|}{ Número de Canais } \\
\cline { 2 - 6 } & \multicolumn{2}{|c|}{$\begin{array}{c}\text { Sub-bacia em 1908 } \\
\text { (a) }\end{array}$} & \multicolumn{2}{c|}{$\begin{array}{c}\text { Sub-bacia em 2012 } \\
\text { (b) }\end{array}$} & $\begin{array}{c}\text { Aterro } \\
\text { (c) }\end{array}$ \\
\cline { 2 - 6 } & 1908 & 2012 & 1908 & 2012 & 2012 \\
\hline $1^{\text {a }}$ & 19 & 9 & 19 & 24 & 9 \\
\hline $2^{\text {a }}$ & 6 & 5 & 6 & 8 & 2 \\
\hline $3^{\text {a }}$ & 1 & 1 & 1 & 1 & 1 \\
\hline TOTAL & $\mathbf{2 6}$ & $\mathbf{1 5}$ & $\mathbf{2 6}$ & $\mathbf{3 3}$ & $\mathbf{1 2}$ \\
\hline Dh & $\mathbf{0 , 4 4}$ & $\mathbf{0 , 2 5}$ & $\mathbf{0 , 4 1}$ & $\mathbf{0 , 5 2}$ & $\mathbf{2 , 5}$ \\
\hline
\end{tabular}

$\mathrm{N}=$ número de canais; $\mathrm{Dh}=\mathrm{N} / \mathrm{km}^{2}$.

(a) considerando a antiga linha de costa $\left(58,3 \mathrm{~km}^{2}\right)$

(b) considerando área atual $\left(63,2 \mathrm{~km}^{2}\right)$, incluindo aterros

(c)Área aterrada $\left(4,8 \mathrm{~km}^{2}\right)$

A figura 3 apresenta as configurações da Sub-bacia do Canal do Cunha: a antiga configuração, ou seja, sem a área aterrada e, o limite atual com a inclusão do aterramento. No rio Timbó, em 1908, existiam 


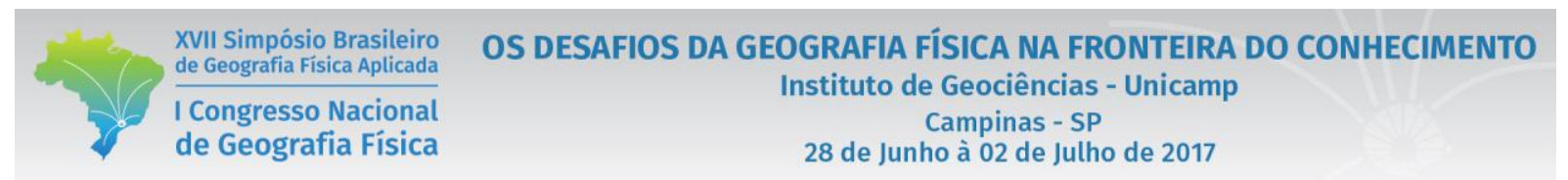

3 afluentes ( $1^{\mathrm{a}}$ ordem), e em 2012, este rio apresenta somente um, próximo à confluência do rio Faria. No rio Faria, há um grande afluente que não está mais presente na paisagem, e o restante dos tributários apresentam-se segmentados, ou seja, cobertos por diversas instalações urbanas que corrompem estes rios. No rio Jacaré há um rio de $1^{\mathrm{a}}$ ordem (drenagem antiga) que não existe mais, por estar coberto ou por ter sido aterrado. Todas estas transformações foram induzidas pela ação humana, pois conforme a urbanização foi se intensificando, os rios foram alterados - quase que numa relação proporcional.

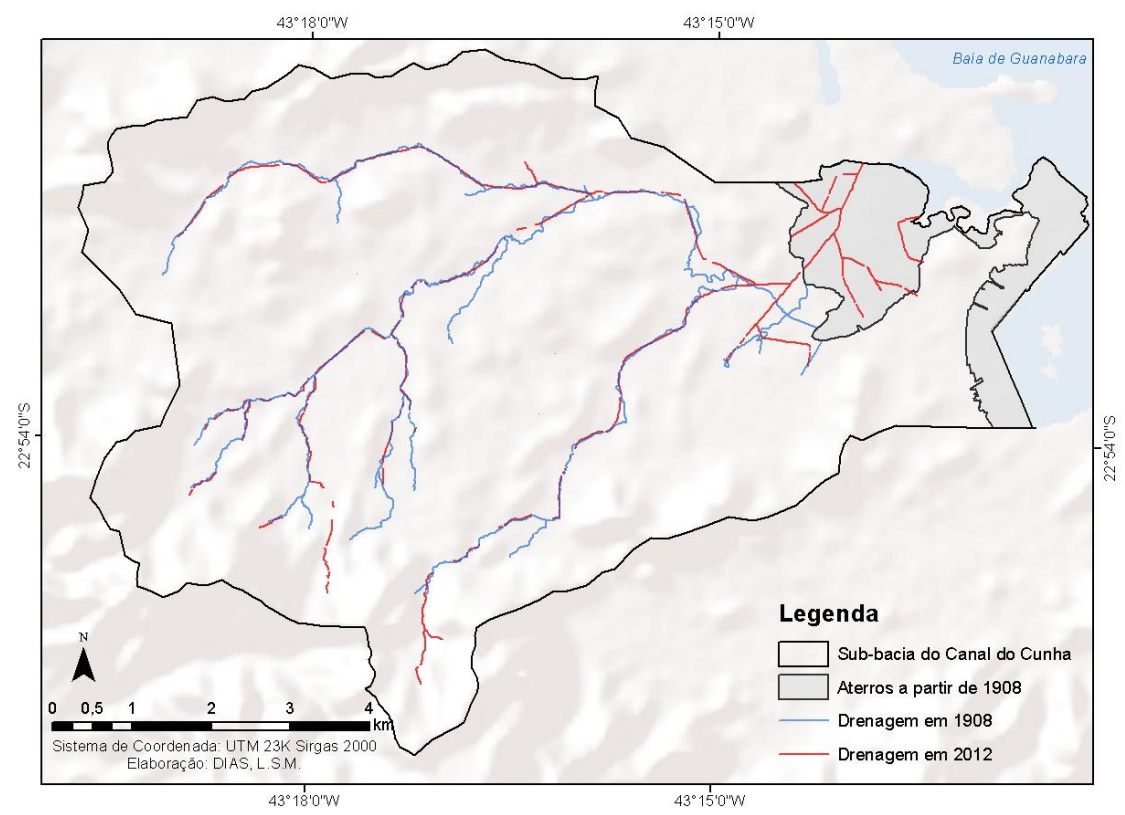

Figura 3: Sobreposição da rede de drenagem de 1908 e 2012, com as configurações dos limites da Sub-bacia (antiga e atual - com a área de aterro incluída).

Ainda, nesta área analisada, os canais de $1^{\mathrm{a}}$ ordem tiveram a redução mais expressiva, com 10 canais a menos. Com a urbanização, alguns canais foram cobertos ou até mesmo aterrados. A figura 4 evidencia um córrego presente na rua Aquidaban, no bairro do Méier, sendo tamponado por concreto armado, durante o período do prefeito do Distrito Federal Henrique Dodsworth (1937 a 1945). Ao considerar a área atual (2012) da sub-bacia constata-se que não há redução do número de canais de $1^{\text {a }}$ ordem e nem de outra ordem, e sim o aumento do número de canais.

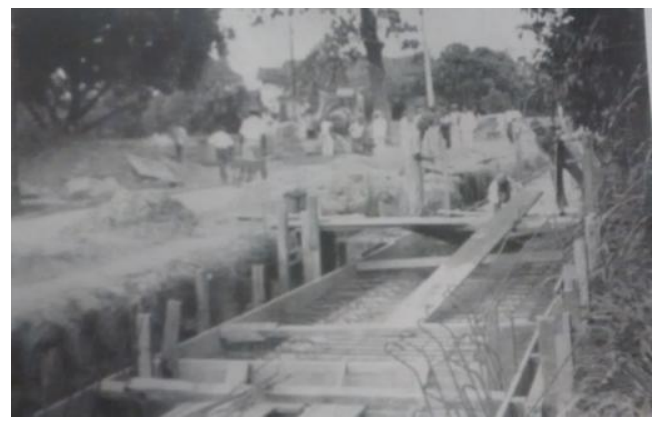


Figura 4: Córrego no Méier que fora coberto por concreto armado. Fonte: Administração Henrique Dodsworth $(1940)^{4}$

A sub-bacia em sua forma atual (2012) apresenta 33 canais fluviais $\left(0,52\right.$ canais $\left./ \mathrm{km}^{2}\right)$ na drenagem em 2012 (tabela 1). Este fato ocorre pela inclusão do aterro, que para drenar a área naturalmente alagada - foi necessário construir canais artificiais, o que é comprovado ao verificar que a área de aterro apresenta 12 canais construídos, e a maior densidade hidrográfica $\left(2,5\right.$ canais $\left./ \mathrm{km}^{2}\right)$. Desse modo, esta área representa um aumento de canais na sub-bacia (11 canais a mais). Os canais não foram todos construídos, pois o canal do Cunha encontra-se nesta área, de forma prolongada e retificada. Além das mudanças evidenciadas no número dos canais, as intervenções também interferiram no comprimento dos rios.

Segundo Vilela \& Mattos (1975), a densidade de drenagem fornece indicação da eficiência de drenagem de bacias hidrográficas e, com isso afirma, que este índice varia de $0,5 \mathrm{~km} / \mathrm{km}^{2}$, para bacias com drenagem pobre, a 3,5 ou mais, para bacias bem drenadas. Os resultados encontrados nas três áreas de análise se aproximaram do que os autores consideram uma bacia pobre em densidade de drenagem (tabela 2). Uma baixa densidade de drenagem indica maior superfície de contribuição, e dessa forma, faz com que o deflúvio demore mais para atingir os canais fluviais (GARCEZ, 1974 apud BORSATO \& MARTONI, $2004)^{3}$.

Com o antigo limite da sub-bacia, a rede de drenagem (1908) obtinha 43,19 km $\left(0,74 \mathrm{~km} / \mathrm{km}^{2}\right)$, desta forma, ao comparar com a drenagem de 2012 (atual) apresenta maior valor. Este fato pode ser explicado pelos cortes dos meandros e a sinuosidade natural dos rios, diferente das formas retificadas da rede de drenagem atual $(27,61 \mathrm{~km})$. A perda da extensão entre estes anos fora de 15,58 km de canais, sendo que a densidade de drenagem passou de $0,74 \mathrm{~km} / \mathrm{km}^{2}$ para $0,47 \mathrm{~km} / \mathrm{km}^{2}$, redução de $36,07 \%$ do comprimento dos canais da sub-bacia. De todo modo, a sub-bacia apresenta densidade de drenagem pobre.

Tabela 2: Comprimento dos canais e densidade de drenagem (Dd).

\begin{tabular}{|c|c|c|c|c|c|c|c|}
\hline \multirow[b]{2}{*}{ Área de Análise } & \multicolumn{3}{|c|}{$\mathrm{L}-\mathrm{km}$} & \multicolumn{2}{|c|}{$\mathrm{Dd}$} & \multicolumn{2}{|c|}{$2012(\%)$} \\
\hline & 1908 & 2012 & $\mathrm{~L}_{1}$ & 1908 & 2012 & $\begin{array}{c}\mathrm{L}- \\
\text { mantido }\end{array}$ & $\begin{array}{c}\mathrm{L}- \\
\text { reduzido }\end{array}$ \\
\hline $\begin{array}{c}\text { Sub bacia em } \\
1908\left(58,3 \mathrm{~km}^{2}\right)\end{array}$ & 43,19 & 27,61 & 15,58 & 0,74 & 0,47 & 63,93 & 36,07 \\
\hline $\begin{array}{c}\text { Sub bacia em } \\
2012\left(63,2 \mathrm{~km}^{2}\right)\end{array}$ & 43,19 & 33,96 & 9,23 & 0,68 & 0,53 & 78,63 & 21,37 \\
\hline Aterro $\left(4,8 \mathrm{~km}^{2}\right)$ & $\mathrm{x}$ & 6,35 & $\mathrm{x}$ & $\mathrm{x}$ & 1,31 & 100 & $\mathrm{x}$ \\
\hline
\end{tabular}

$\mathrm{L}=$ comprimentos do canal $; \mathrm{L}_{1}=\mathrm{L}$ perdido $; \mathrm{Dd}=\mathrm{km} / \mathrm{km}^{2}$ 
Ao analisar a drenagem na configuração atual da Sub-bacia, observa-se que mesmo com o acréscimo da área de aterro $\left(4,8 \mathrm{~km}^{2}\right)$ e a presença de outros canais artificiais, há redução no comprimento dos canais. A drenagem atual apresenta $33,96 \mathrm{~km}\left(0,53 \mathrm{~km} / \mathrm{km}^{2}\right)$, ecomparada com a antiga rede de drenagem $\left(0,68 \mathrm{~km} / \mathrm{km}^{2}\right)$, verificou-se redução de $21,37 \%$ do comprimento dos canais. A redução, nesse caso, é menos expressiva por se considerar a área de aterro $(6,35 \mathrm{~km}$ de canais). Esta área não era existente no início do século XX, sendo assim, é uma área peculiar da atual configuração da sub-bacia.

Ao expandir o espaço físico da cidade em direção ao subúrbio, ocorreram sucessivos aterros, e em consequência, houvera a construção de novos canais - como já foi exposto anteriormente. Esta área que já fora ocupada pelo extinto aeroporto de Manguinhos, atualmente é ocupada pela refinaria de Manguinhos, parte da zona portuária, vias públicas, favelas (Manguinhos e Maré), etc. A densidade de drenagem dessa área $\left(1,31 \mathrm{~km} / \mathrm{km}^{2}\right)$ é a mais alta ao confrontar com às demais áreas.

De modo geral, a densidade de drenagem que apresenta o valor menos expressivo é a rede de drenagem em $2012\left(0,47 \mathrm{~km} / \mathrm{km}^{2}\right)$ com a área da antiga Sub-bacia (1908). Este valor aumenta para 0,53 $\mathrm{km} / \mathrm{km}^{2}$ na configuração da atual sub-bacia, porém mesmo com o acréscimo de novos canais (área de aterro), os resultados de densidade de drenagem ficaram abaixo dos valores da drenagem em 1908. Este fato evidencia que os trabalhos realizados pelo Departamento Nacional de Obras de Saneamento, Superintendência de Urbanização e Saneamento, e outros, trouxeram mudanças significativas para a rede de drenagem, contribuindo para reduzir a baixa densidade de drenagem da sub-bacia.

A drenagem em 1908 apresenta-se sinuosa, com presença de meandros ao longo de todos os principais cursos d'água (rio Faria, Timbó, Jacaré e Cunha), e ao longo de um pouco mais de um século, encontra-se totalmente alterado. Para Assumpção \& Marçal (2012), a retificação de rios é um processo no qual os canais fluviais são artificialmente alterados na sua forma através do aprofundamento e/ou alargamento da calha fluvial e da retirada de meandros alterando, sobremaneira, a forma em planta e o perfil longitudinal dos canais, o que interfere direta e indiretamente em todo o sistema fluvial da bacia. A figura 5apresenta, em detalhe, quatro áreas amostrais sobre as mudanças ocorridas no comprimento e número dos canais fluviais entre os anos de 1908 e 2012. 

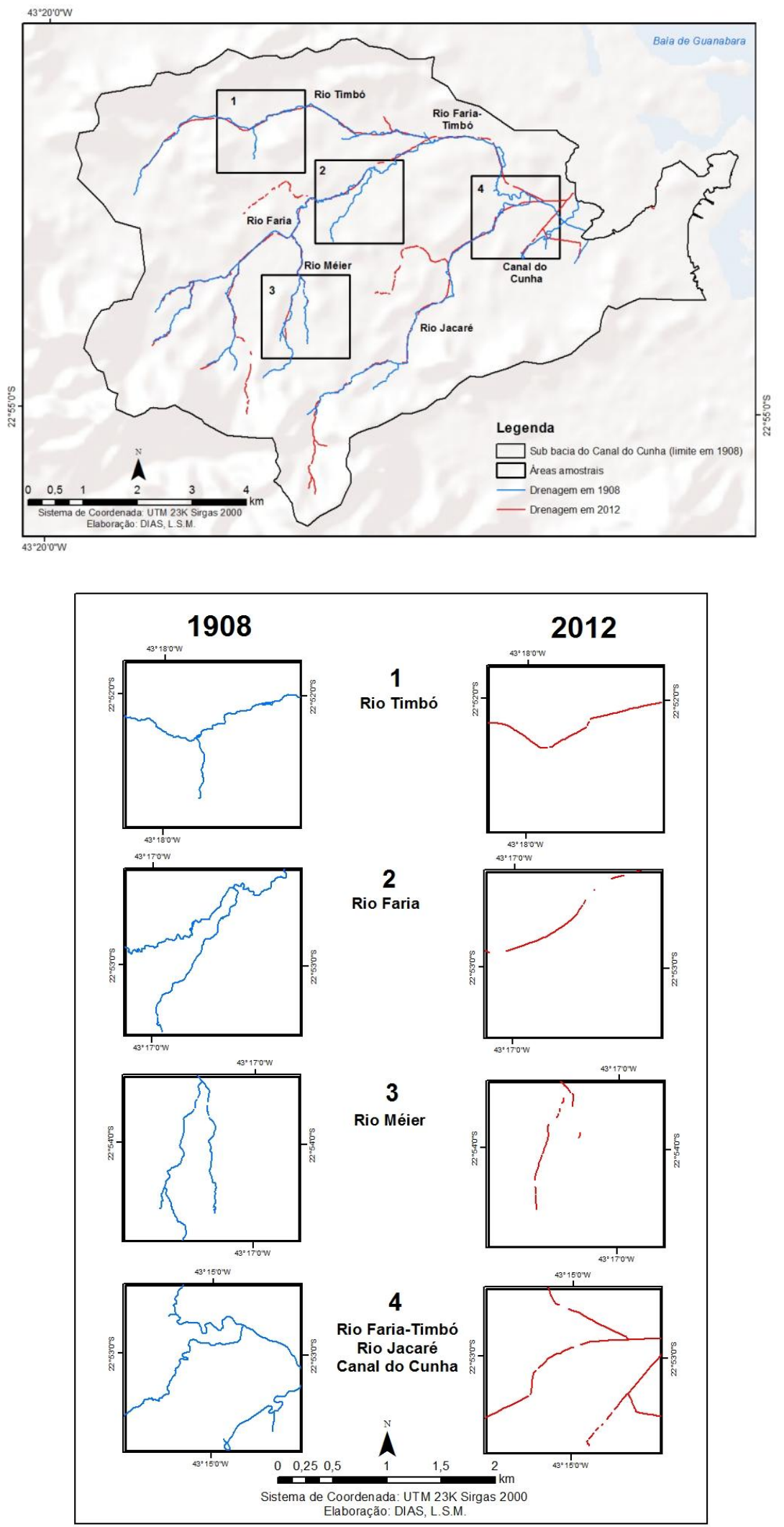

Figura 5: Áreas amostrais da rede de drenagem da Sub-bacia, em 1908 e 2012. 
A amostra (1) apresenta trecho do rio Timbó, onde em 1908 havia um afluente, no bairro de Pilares, e atualmente encontra-se coberto; (2) tributário do rio Faria que fora, como a outra situação amostral, aterrado ou tamponado, e o rio Faria perdera seus meandros e sua sinuosidade natural apresentando-se de forma retificada; (3) o rio Méier, afluente do rio Faria, fora modificado através das obras de engenharia - pela canalização e retificação -, assim como construção de vias e prédios por cima do canal; e por fim, (4) confluência dos rios Faria e Timbó e o Canal do Cunha, apresenta forma demasiadamente distintas entre os anos apresentados. Em 1908, tanto o rio Timbó quanto o rio Faria tinham a forma do canal sinuosa com a presença de meandros tortuosos. Em 2012 (atual), não existem mais meandros nem sinuosidades, apenas canais retificados. O mesmo processo ocorrera com o Canal do Cunha. Segundo Cunha (2011), os impactos causados pelas obras de engenharia são, na maioria, fenômenos localizados que ocasionam efeitos em cadeia, com reações - muitas vezes - irreversíveis.

\section{Considerações Finais}

A pesquisa demonstra que a rede de drenagem - submetida à urbanização -apresentou alterações no padrão de drenagem ao longo do século XX. O resultado das intervenções antrópicas gerou transformações no padrão dos canais fluviais, onde estes se tornaram artificializados.

Os resultados de densidade de drenagem e densidade hidrográfica apresentaram alterações na comparação têmporo-espacial. Ao comparar com a configuração atual da Sub-bacia, a densidade hidrográfica apresentou aumento no valor: de 0,41 canais $/ \mathrm{km}^{2}$ passou a ter 0,52 canais $/ \mathrm{km}^{2}$. Este aumento ocorreu pela construção de novos canais na área de aterro. Porém, a densidade de drenagem apresentou reduções, devido ao encurtamento, tamponamento e aterramento dos rios.

A drenagem da Sub-bacia, em 1908, apresentava 43,19 $\mathrm{km}$ de rios $\left(0,74 \mathrm{~km} / \mathrm{km}^{2}\right)$ sinuosos e meandrosos. Com as intervenções antrópicas realizadas nos rios, este número foi reduzido para 27,61 km de canais $\left(0,47 \mathrm{~km}^{2} / \mathrm{km}\right)$ - na antiga configuração da Sub-bacia, ou seja, 15,58 km de drenagem a menos. Estas reduções no comprimento de canais podem favorecer o acumulo e fluxo d'água em eventos de pluviosidade ocasionando enchentes urbanas.

As intervenções antrópicas podem ser identificadas, nesta metodologia com base em cartografia histórica, podendo ser avaliadas a magnitude do processo de urbanização frente aos canais fluviais. Desse modo, poderá ser utilizada como ferramenta de análise à projetos de recuperação ambiental, de modo a servir como suporte de ações. 
${ }^{1}$ HORTON, R.E. Erosional Development of Streams and Their Drainage Basins; Hydrophysical Approach to Quantitative Mor phology. Bull Geol Soc Am 56:275-370, 1945.

${ }^{2}$ LINSLEY, R.K. Jr. et al. Hydrology for Engineers.2 Hill.McGraw-Hill Series in Water Resources and Environmental Engineering.ed. New York: McGraw, 1975.

${ }^{3}$ STRAHLER, A.N. Hypsometric (area-altitude) analysis and erosional topography. Geological Society of America Bulletin, v. 63, p.1117-1142, 1952.

${ }^{4}$ ADMINISTRAÇÃO HENRIQUE DODSWORTH. Revista Municipal de Engenharia. N. 4. Volume VII. Julho. Rio de Janeiro, 1940. 255-340 p.

\section{Bibliografia}

ANTONELI, V. THOMAZ, E.L..Caracterização do Meio Físico da Bacia do Arroio Boa Vista - GuamirangaPR. Revista Caminhos de Geografia. v. 8, n. 21 Junho. Uberlândia, 2007. 46 - 58 p.

ASSUMPÇÃO, A. P.; MARÇAL, M. S. Retificação dos Canais Fluviais e Mudanças Geomorfológicas na Planície do rio Macaé (RJ). Revista de Geografia (UFPE) V. 29, No. 3. 2012. 19 - 36 p.

BORSATO, F. H. \& MARTORI, A. M.. Estudo da Fisiografia das Bacias Hidrográficas Urbanas no Município de Maringá, Estado do Paraná. Acta Scientiarum. Human and Social Sciences. v. 26, n. 2. Maringá, 2004. 273-285 p.

CENSO (2010). Armazém de Dados. Prefeitura do Rio de Janeiro. Instituto Pereira Passos. Disponível em <www.armazemdedados.rio.rj.gov.br>. Acesso em 15 de abril de 2015.

CHRISTOFOLETTI, A. Análise de Bacias Hidrográficas. In: Geomorfologia. Editora Edgard Blucher, 2a edição. São Paulo, 1980. 102 - 127 p.

CUNHA, S. B. Morfologia dos Canais Urbanos nos Trópicos Úmidos: a Experiência no Brasil. VI Seminário Latino-Americano de Geografia Física II Seminário Ibero-Americano de Geografia Física Universidade de Coimbra. Maio, $2010.14 \mathrm{p}$.

GUERRA, A. T. Novo Dicionário Geológico-Geomorfológico. Antônio Teixeira Guerra \& Antonio José Teixeira Guerra (orgs.). $6^{\text {a }}$ edição. Editora Bertrand. Rio de Janeiro, 2008.439 p.

IBGE - Instituto Brasileiro de Geografia e Estatística.Manual Técnico de Geomorfologia / IBGE, Coordenação de Recursos Naturais e Estudos Ambientais. - 2. ed. - Rio de Janeiro : IBGE, 2009.

VILELA, S. M.; MATTOS, A. Hidrologia Aplicada. São Paulo: Mc Graw Hill do Brasil, 1975. 245 p.

\section{Agradecimentos}

$\mathrm{O}$ autor principal agradece à CAPES e à FAPERJ pelo apoio financeiro como bolsa de mestrado no PPGG da UFF. 